\title{
Tubule Formation
}

National Cancer Institute

\section{Source}

National Cancer Institute. Tubule Formation. NCI Thesaurus. Code C62448.

The presence of malignant tubular formations which are thought to represent malignant counterparts of the terminal ductal-lobular units of the breast. 